\title{
Providing Access, Serving Programs, and Strengthening Inclusiveness: A Tripartite Model for Graduate Schools
}

\author{
Sweeney Windchief \\ Montana State University
}

U. S. A.

ABSTRACT: This paper addresses critical issues related to student support and how different departments define inclusivity for graduate students in the context of American higher education. A four-framed, comprehensive, tripartite model is provided to guide institutions by assisting graduate school administrators, who are charged with improving inclusiveness regarding academic programs and departments. This model suggests services and support in precise ways by delineating the different needs that programs have. Finally, this manuscript concludes with a discussion on encouraging programs and departments to deliberate on why they value diversity.

\section{KEYWORDS: inclusiveness, diversity, resource allocation, graduate school} leadership, higher education

\author{
Theoretical Foundation \\ A Tripartite Framework \\ Applying the Tripartite Model \\ Contribution to Practice \\ Conclusion \\ Notes \\ References \\ Author Contact
}

For institutions of higher learning in the context of the United States, the objective of creating and maintaining opportunities for underrepresented students is to benefit the future workforce. In 2008 the National Science Foundation was promoting inclusivity through diverse ideas and perspectives as being vital to the nation's research enterprise (NSF, 2008). Scholarship in the area of supporting diversity initiatives suggests that broadening participation, diversity, and inclusivity benefits all students who are engaged in higher learning (Gurin, Dey, Hurtado, \& Gurin, 2002; Pascarella \& Terenzini, 2005). This paper provides a rubric to assess the degree of inclusiveness in graduate schools based on templates devised at a public, research-intensive university in the Rocky Mountain region of the United States. It also suggests different ways of enhancing diversity for four different types of graduate programs by intersecting the degree of inclusiveness and the financial conditions of the academic units. The guidelines provided in this manuscript are intended to serve those institutions whose mission statements 
support equitable access to graduate school, diversity, and inclusivity, and who are able to award diversity funding in alignment with local, state, and federal laws.

\section{Theoretical Foundation}

The theoretical foundation for this manuscript is couched in organizational theory that supports diversity initiatives at American institutions of higher education, particularly in graduate schools. As Gurin et al. (2002) conclude in their well cited article, students' experiences with diversity have a consistent and meaningful effect on both learning and democracy outcomes of a college education, supporting the benefits of diversity. Furthermore, when there is a lack of diversity, students from underrepresented communities in higher education can be tokenized, given undue attention, leading to further stereotyping by majority students. Conversely, if students experience diversity as a result of their post-secondary education, they benefit by developing the relational skills needed in the workplace (Gurin, 2002) The literature supporting diversity in higher education is substantive and is often researched by specific academic programs or under the umbrella of the science, technology, engineering, and math (STEM) fields (AllenRamdial \& Campbell, 2014; Briggs, 2017; Whittaker \& Montgomery, 2014). The literature becomes less prevalent when speaking more broadly across populations of graduate students at any one institution. However, there is certainly work that informs graduate programs that seek to develop a culture of inclusion. In a very pragmatic article, Duranczyk, Franko, Osifuye, Barton, and Higbee (2015) give very specific advice in developing a welcoming campus climate for historically underrepresented students to include making use of cohort models, excluding the Graduate Record Examination (GRE), adopting twice-a-semester advising, and attending to students' professional development. In addition, The Council of Graduate Schools (CGS) provides pragmatic guidance and resources for graduate school deans in terms of diversity and inclusivity specifically (Diversity and Inclusion, n.d.).

A review of graduate college and graduate school websites in the U.S. reveals that, along with progressing the mission and vision of their respective institutions, graduate school administrators serve multiple roles within the context of a university. These roles include recruitment, admission, managing policies and procedures, and overseeing funding to include assistantship and fellowship opportunities. Administrators spend time and resources managing thesis and dissertation submission structures and promoting graduation information. In addition, graduate school deans and leaders are encouraged by the Council of Graduate Schools ${ }^{1}$ to engage in meaningful action related to best practices including improving attrition and completion rates, developing career pathways, and enhancing professional development and inclusiveness (Inclusiveness, n.d.).

A comprehensive graduate school program that works toward supporting successful recruitment, matriculation, persistence, and graduation includes services for underrepresented groups in graduate education. Given the fact of gender disparities being magnified in particular academic disciplines and racial disparities in others, inclusivity can only be accomplished when in alignment with specific departmental needs and definitions. What must be considered is how inclusiveness is understood across 
academic disciplines. In short, inclusivity in engineering is not inclusivity in the humanities nor in education, etc. Consequently, people must consider an assessment of the resources that are available to fulfill their respective missions and visions as they relate to inclusivity and equity broadly defined. Graduate programs have different resources that can be used in different ways to meet the multiple needs of all stakeholders.

Affirmative action is clarified in the literature as follows: "To increase racial and ethnic student body diversity, institutions of higher education have used affirmative action-or the consideration of race or ethnicity as one factor, among others-in admissions decisions" (Garces, 2012, p. 94). Affirmative action can include financial support for those who are identified as low socioeconomic status (SES), mentoring programs for those with specific needs, and student services for those who enter an institution with a campus climate detrimental to their educational experience (Villalpando, 2003). These institutional actions potentially impact educational leaders and, for our purposes here, graduate school administrators and deans.

In order to address the complexity of context, differing definitions of inclusiveness, and funding differentials, an assessment of departmental needs must be made. The following conceptual framework is provided with the intent of helping departments and programs meet their own goals as they relate to diversity. Also provided is a rubric for adjusting financial support for equity and diversity to assist graduate programs in creating avenues of access in specific ways. In other words, this manuscript provides a model that addresses racial inequities by using resources across graduate school programs and/or departments that meet their needs for inclusivity and institutional mission.

\section{A Tripartite Framework for Graduate Program Diversity}

The conceptual framework for this paper has a tripartite base including (a) evidence for supporting inclusiveness in graduate education, (b) the reality of finite resources that are used to encourage diversity, and (c) variability across different academic programs. as shown in Figure 1. 


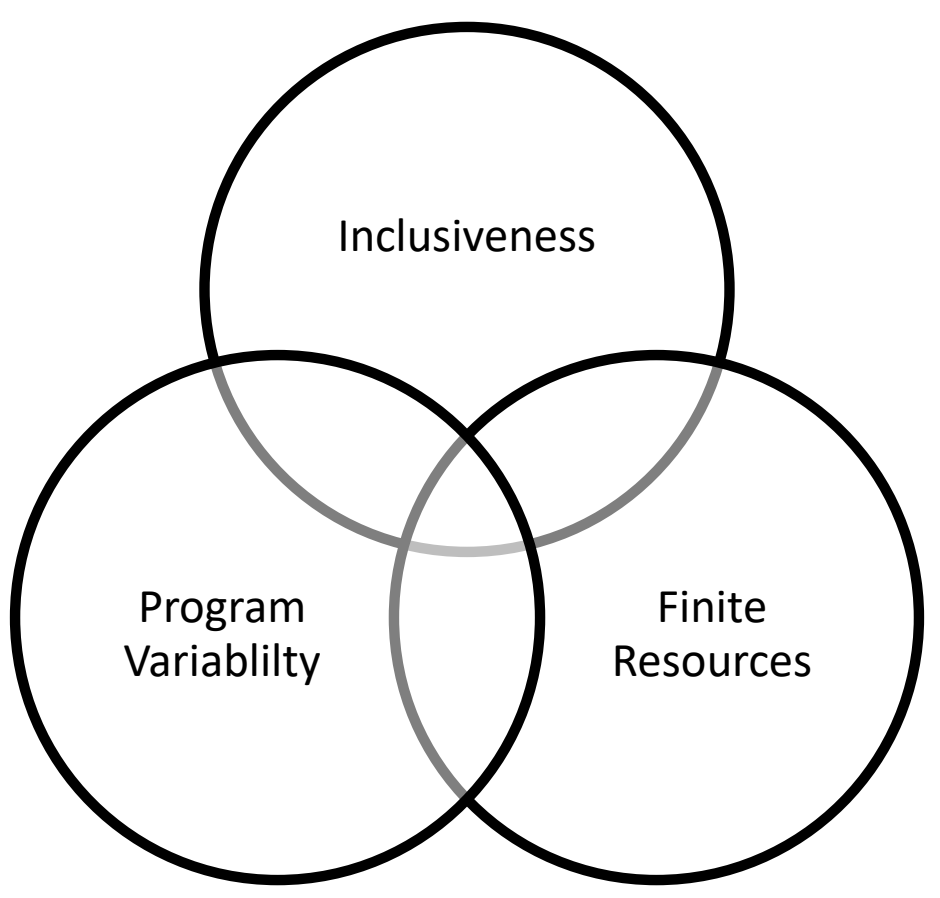

Figure 1. Tripartite conceptual framework: Evidence for supporting inclusiveness in graduate education, the reality of finite resources, and variability across different academic programs.

Because colleges and departments are unique entities with particularized needs, they are discussed and viewed separately in this manuscript. The interwoven nature of inclusiveness, the limitations of finite resources, and the differing needs of programs as they relate to diversity are considered. Finally, in order to inform graduate schools, academic departments, and programs that want to reimagine how they will become more inclusive, the structural, human resource, political, and symbolic frames (Bolman \& Deal, 2017) that inform programmatic change at the organizational level are considered.

\section{Evidence for Supporting Equity and Diversity in Graduate Programs}

In the United States, student enrollment data show that, of all doctoral degrees awarded in the year 2009/2010, only $7.4 \%$ were awarded to African Americans, $5.8 \%$ were awarded to Hispanics/Latinos, and .7\% were awarded to American Indians/Alaska Natives (U.S. Department of Education 2011). A review of the statistical data, specifically the number of doctoral degrees conferred to U.S. residents by race/ethnicity for the 10 years between 1999-2000 and 2009-10, demonstrates that, though these numbers are increasing, they are still very low, as can be observed in Figure 2. 


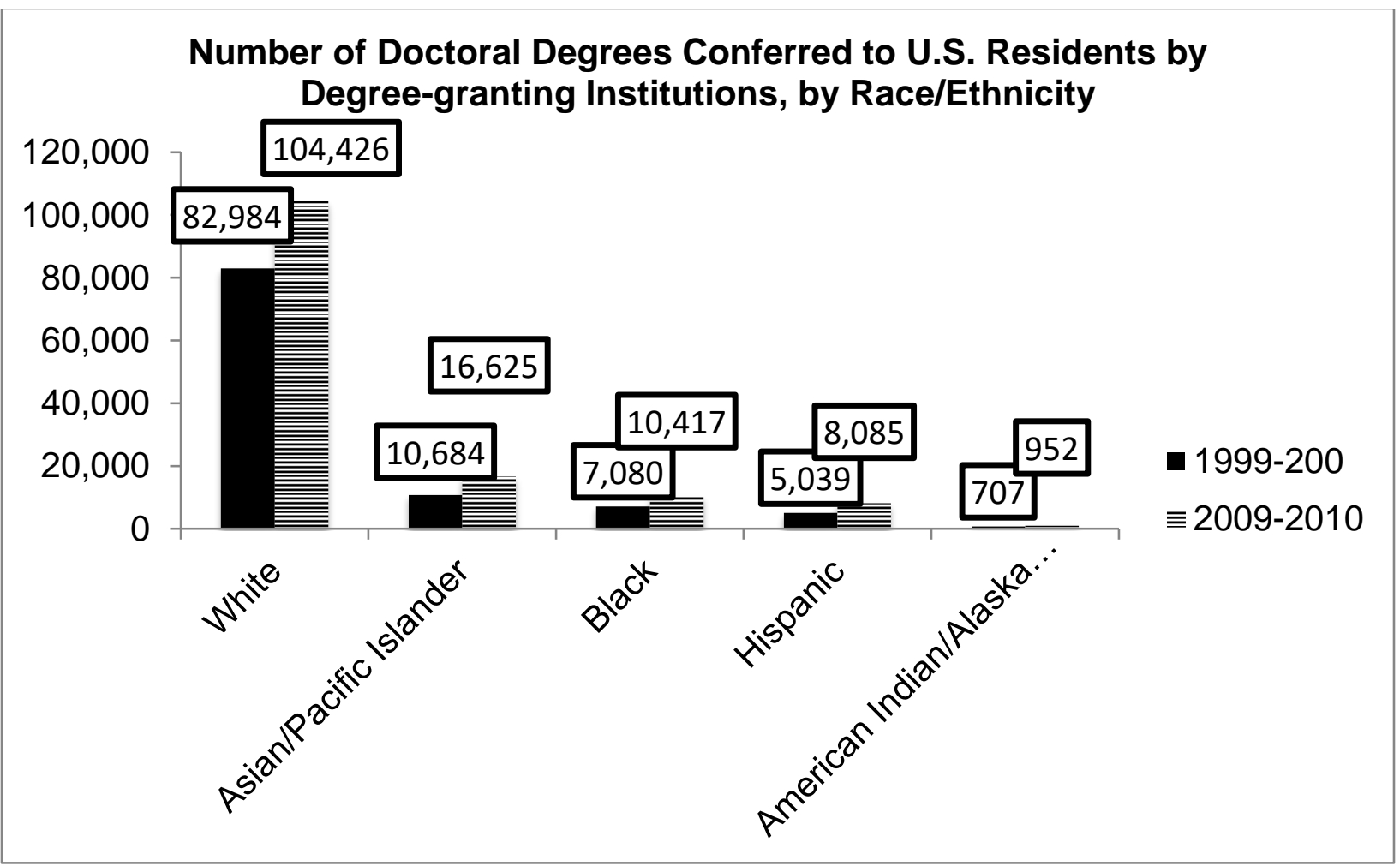

Figure 2. Number of doctoral degrees conferred to U.S. residents by degree-granting institutions, delineated by racial and ethnic categories as established by the National Center for Education Statistics in "Integrated Postsecondary Education Data System," National Center for Education Statistics, 2011, U.S. Department of Education.

More recently the number of doctoral degrees earned in the United States by ethnicity in has changed to benefit some groups more than others. In the academic year $2015 / 16$, students who self-identified as White had an increase of $2.6 \%$, and the Asian/Pacific Islander demographic rose by $17.8 \%$. The Black demographic rose by $28.3 \%$, the Hispanic population by $45.5 \%$, while the American Indian/Alaska Native population, by contrast, dropped by $15.1 \%$, as shown in Figure 3 


\section{Doctoral Degrees Earned in the United States by Ethnicity 2015/16}

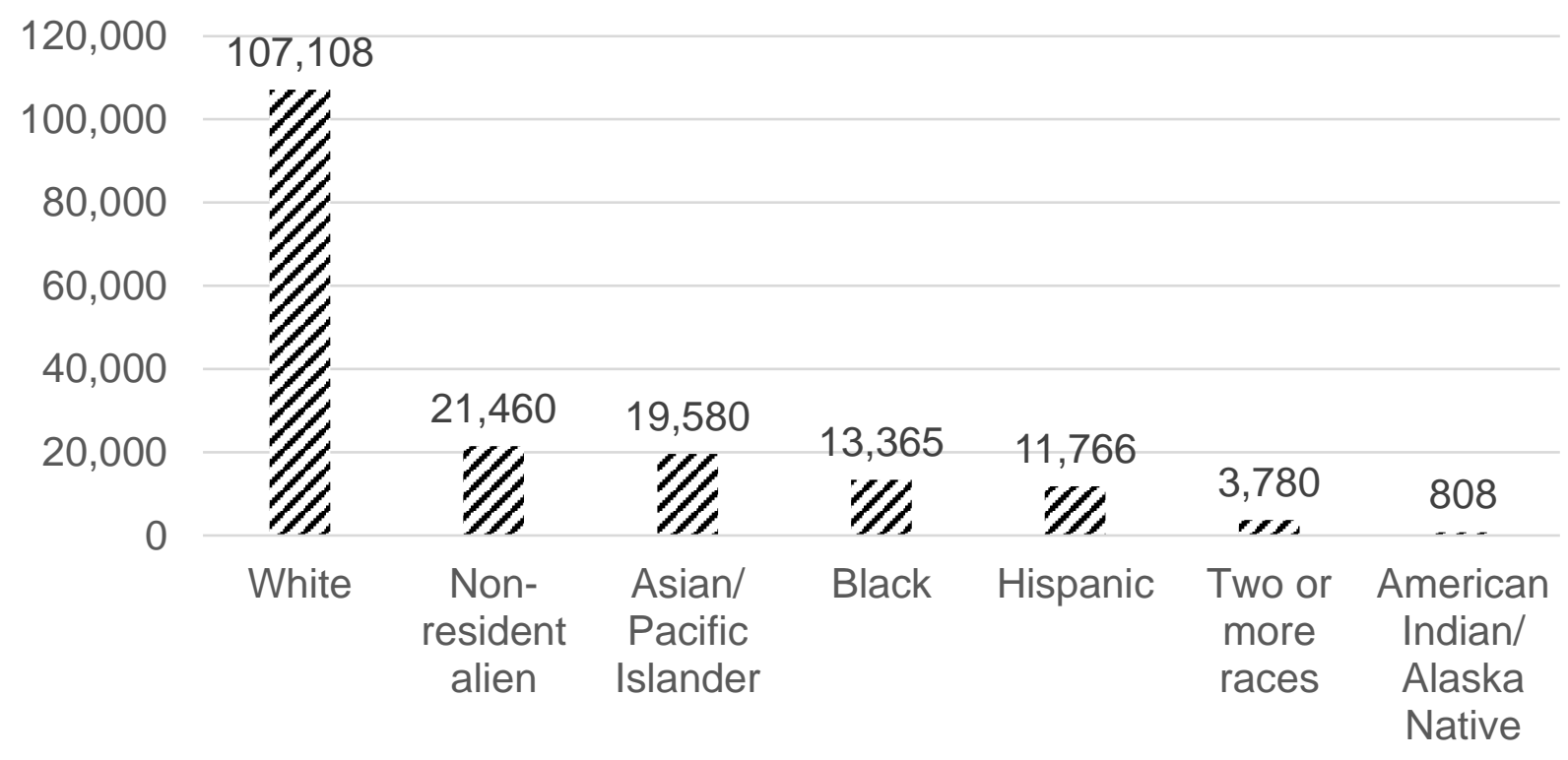

Figure 3. The number of doctoral degrees earned in higher education in the United States in $2015 / 16$, distinguished by ethnicity (NCES., n.d.).

In reviewing the literature related to diversity in higher education, researchers point out the impact of banning affirmative action and the influence that has on graduate school enrollment.

In sum, the findings from this study suggest that the trend toward banning affirmative action through the use of the state ballot is causing declines in the enrollment of students of color in graduate programs at a time when the racial and ethnic diversity of the U.S. population is increasing (Garces, 2012, p.126).

Others addressing this issue study and report on campus racial climate and applied policy and practice (Milem, Clayton-Pedersen, Hurtado, \& Allen, 1998). Furthermore, closely related studies illuminate the benefits of diversity across divisions in graduate education (Milem, 2003). At the state level, there have been affirmative action bans implemented using different methods, as stated by Garces (2012):

Moreover, seven states currently ban affirmative action practices. Of these, five (Arizona, California, Washington, Michigan, and Nebraska) implemented the bans through voter-approved initiatives or referenda; two others (Florida and New Hampshire) banned the practice by executive decision or legislative vote respectively (p. 94).

Concerns around the concept of affirmative action are brought up in the literature. These concerns include a colorblind rationale that is challenged using critical race theory (Yosso, Parker, Solórzano, \& Lynn, 2004), showing how it discourages meritocratic values and principles (Augoustinos, Tuffin, \& Every, 2005), and how it promotes actions that reify 
systematic imbalance (Goldstein Hode \& Meisenbach, 2017). The social construction of race and the unique position of the Asian American demographic during the attempted reinstatement of affirmative action in California in 2014 (Inouye, 2016), as well as concerns about proportionality (Chu, 2016), serve to complicate the conversation even beyond the context of Fisher v. Texas, which ruled that strict scrutiny should be applied to determine the constitutionality of the University of Texas' race-sensitive admissions policy.

Though affirmative action policies are similar to one another, they do not appropriately complicate inclusiveness, nor do they prohibit practices that serve historically underrepresented populations. Park and Liu (2014) center the Asian American experience, trouble out the concept of meritocracy, and redefine the principle of critical mass in ways that challenge the standard academic narrative.

Within every state that bans affirmative action, there are programs that serve students from underrepresented communities in higher education. These programs are observed in multiple forms including recruitment events, external funding, and multiple positions within college and university administrative structures, in some cases at the vice-presidential level. Often referred to as Chief Diversity Officers, these educational leaders are regularly given executive responsibilities. They have expertise in the field of diversity, collaborate with other entities on campus, and promote organizational change towards the goal of a more inclusive campus. Nevertheless, historically underrepresented students are still underrepresented, affirmative action may (or may not) be instituted, and institutions still have an espoused interest in inclusivity, as many colleges and universities communicate their commitment on their websites.

\section{The Practical Argument and the Reality of Finite Resources}

This paper is offered with the goal of protecting the limited and finite resources that colleges and universities use to support inclusivity at the graduate level. Because institutional budgets are often tight, calculated spending and fiscal accountability are of great concern to institutional leaders. In this model, fiscal accountability is addressed by recognizing different programmatic/departmental strengths as well as weaknesses that are directly connected to success regarding the recruitment, retention, and graduation of historically underrepresented students. It matters not that one is a vice president, a dean, a director, or a faculty member: everyone is accountable to someone else for the financial decisions that are made in any institution of higher education. It is in the best interest of any entity to avoid arbitrary and capricious awarding of financial support to programs and departments. Because there is so much scrutiny around diversity support, both graduate schools and academic programs need to reflect institutional missions, address departmental needs, and be in alignment with state and federal laws.

\section{Differing Departmental Needs}

Typically, science, technology, engineering, and mathematics (STEM) fields are lacking in their numbers of women and people of color, with the exception of Asians ${ }^{1}$. Hence the term "Underrepresented Minority" (URM) is often used. The distinction of URM typically includes African Americans, Hispanics/Latinos, and American Indians/Alaska Natives. STEM programs often have the resources to fund a student's doctoral program as a matter of common practice regardless of race, ethnicity, gender, nationality, or 
socioeconomic status. If one is offered acceptance into a STEM degree program, the acceptance may very well include room, board, books, tuition, and other expenses and even include a stipend. In essence, being a doctoral student is akin to landing a job.

Conversely, in fields like education, ethnic studies, or various areas in the humanities, acceptance into a doctoral program leaves the student responsible for the costs associated with attending graduate school. If departments or programs in these fields are interested in benefitting from a diverse program, they most certainly have different needs that the STEM fields. According to the U.S. Department of Education National Center for Education Statistics Integrated Postsecondary Education Data System Completions Survey, 2001-10, there is a magnification of disparity for URMs in the STEM fields. In the first place, the STEM departments/programs that graduate schools work with most likely would need help recruiting URMs into their application pool such that they yield a number of students that can bring different perspectives into their field. If they are successful in recruitment but not as successful in graduating these students, culturally attuned support for retention would be needed. According to Estrada et al. (2016), this can include creating strategic partnerships, restructuring curriculum to activate learning, addressing resource differences among students, and tapping into students' creative abilities.

In the case of education, ethnic studies, or humanities departments/programs, it is likely that they have students from underrepresented communities who apply and are successfully admitted into the program; however, these students may not be able to pay the cost of attendance and may exit the program because they simply cannot afford it. The prohibitive costs may include room, board, books, tuition, transportation, childcare, health insurance, and perhaps supporting a larger extended family. This kind of reality often manifests in a dearth of matriculation or of completion due to financial distress. In sum, the main issue in these fields is merely being able to afford graduate study. In order to improve the overall success of URMs in graduate school, therefore, it serves institutions well to create a structure by which programs are awarded funding in ways that help them support underrepresented students in the precise ways that the programs/departments need it.

\section{Applying the Tripartite Model}

In order to be successful in the recruitment, matriculation, and graduation of URMs, it is necessary that graduate school administrators be precise and methodical in the support they offer their constituencies. This is best achieved by categorizing departmental/programmatic success. This means that graduate school administrators need to assess all departments' recruitment and retention to see exactly what URM representation looks like when delineated by academic program (Estrada et al., 2016), which can be accomplished by ranking and ordering according to diversity and funding. After ranking and ordering shows which programs are successful and which ones are struggling in terms of diversity, they can be placed in one of two categories: those above the mean when compared to their peer programs and those below the mean. After making these categorizations, practitioners will be able to assess the kinds of resources needed 
to effect change. Departments and programs can then be evaluated as to which programs offer financial packages to students that are above and beyond the cost of tuition. The same programs can be compared to their peers as to the amount offered and placed into one of two categories: High Funding (those that automatically provide support above tuition) and Low Funding (those that provide funding ranging from less than the cost of tuition to none at all).

In order to serve programs efficiently regarding student support and diversity, graduate school administrators will need to compare and contrast what these programs look like according to the numbers that represent diversity and student support as delineated in Table 1.

Table 1. Four-Framed Rubric for Graduate Schools

\begin{tabular}{|l|l|l|}
\hline $\begin{array}{l}\text { Tripartite Frame, } \\
\text { Emphasis }\end{array}$ & Diversity High & Diversity Low \\
\hline Funding High & Programs & \\
\hline & A & Programs \\
& E & B \\
\hline Funding Low & Programs & F \\
& C & Programs \\
& G & D \\
\hline
\end{tabular}

Once this is accomplished, practitioners can then formulate how to best serve these departments and programs. If programs have a high number of URMs $(A, E$,$) they will$ want to promote and highlight this success. This can be done in multiple ways including nominating these departments and key faculty for diversity awards, offering assistance in gathering information for program self-studies and subsequent information for accreditation purposes, and recognizing them as institutional exemplars, thus incentivizing programs to compete for distinction in terms of diversity.

Luther, Seeberger, Phelan, and Simpson (2011) provide a model for creating such an award including defining the type of award and what might be incorporated in an inclusivity award. Moreover, they offer pragmatic and practical information regarding the promotion of the award connected to the institutional goals, the nomination process, and an evaluation that is accomplished through an institutional committee. Incentivizing diversity through public commendation can be done at both individual and program/department levels. At the individual level, it can include those practices that are connected to professional advancement for both student affairs professionals and administration as well as for faculty, including a letter of commendation stating specifically what individuals accomplished (and how they did it) to be placed in their professional portfolio or dossier. At the program/department level, the award may be a symbolic representation such as a plaque or certificate of recognition. In either case, it would be most appropriate to give the award during a gathering of stakeholders so that is it 
witnessed by those that contributed as well as those that aspire to with the award the following year. (SeeTable 2.)

Table 2. Emphasis: Promotion of Programs and People as Exemplars

\begin{tabular}{|l|l|}
\hline $\begin{array}{l}\text { Emphasis: Promotion } \\
\text { of programs and people } \\
\text { as exemplars }\end{array}$ & \begin{tabular}{l} 
Diversity High \\
\hline Funding High
\end{tabular} \\
\hline & $\begin{aligned} \text { Programs A, E } \\
\text { - Nominate departments, programs, and key } \\
\text { staff/faculty for awards } \\
\text { - Present letters of commendation } \\
\text { - Provide institutional recognition as exemplars } \\
\end{aligned}$ \\
& during a public event \\
\hline
\end{tabular}

For programs that score high in the area of student funding, but low in the area of URM representation, the graduate school can offer to assist in developing recruitment strategies to include access to various pools of students who are qualified for and interested in those academic programs. These pools may include the GRE Search Service, the National Name Exchange, the McNair Directory, and the California Forums for Diversity. Graduate schools can assist in other ways as well, such as helping in the development of culturally attuned programming and mentorship program support.

Because there is overlap in some academic disciplines, it may be helpful to promote the idea that related programs/departments pool resources and hire a recruiter to represent particular factions. The STEM fields or the health-related fields may benefit from this practice. Regardless of how a recruiter is supported, it is imperative that he or she know the programs well enough to speak to prospective students about program specifics. Application requirements, deadlines, standardized testing thresholds, tuition, cost of attendance, and time to degree are all pertinent information needed for aligning prospective students with appropriate programs. (See Table 3.) 
Table 3. Recruitment Emphasis for Programs with a High Level of Student Support But a Low Level of Diversity

\begin{tabular}{|c|c|}
\hline Emphasis: Recruitment & Diversity Low \\
\hline Funding High & $\begin{array}{l}\text { Programs B, F } \\
\text { - Assist in developing recruitment strategies } \\
\text { - Attend diversity recruitment events } \\
\text { - Provide student recruitment lists to faculty/staff }\end{array}$ \\
\hline
\end{tabular}

For programs/departments that have limited funding for their students but have high numbers of URMs when compared to their peers, graduate school administrators can assist in gathering resources for assistantships and fellowships. They can offer to help write grant proposals that would support URMs in these programs, assist in searching for external fellowships, and seek opportunities for these students to apply for other assistance such as fee waivers and scholarships, as demarcated in Table 4.

Table 4. Emphasis on Financial Support for Programs with a High Level of Diversity But a Low Level of Funding.

\begin{tabular}{|l|l|}
\hline $\begin{array}{l}\text { Emphasis: Financial } \\
\text { Support }\end{array}$ & Diversity High \\
\hline Funding Low & $\begin{aligned} \text { Programs C, G } \\
\text { - Gather resources for assistantships } \\
\text { - Gather resources for fellowships } \\
\text { - Assist in grant proposal writing } \\
\text { - Seek opportunities for students to apply for other } \\
\end{aligned} \quad$ financial assistance \\
\hline
\end{tabular}

Even though colleges and universities may have programs in place, there is no guarantee that these programs are well organized or being given the appropriate resources to effect change (Jones, Yonezawa, Ballesteros, \& Mehan, 2002). The average monthly student loan payment (for borrowers aged 20 to 30 years) is $\$ 351$; the median monthly student loan payment (for borrowers aged 20 to 30 years) is \$203 (U.S. Student Loan Debt Statistics, 2017). Students are becoming aware that education may not be worth the cost unless there is a substantial subsidy in the form of an assistantship, 
fellowship, or help through other means. If indeed departments/programs are committed to inclusivity, they are then committed to helping students attend their university in ways that are not financially debilitating for years to come. This includes thinking about nontraditional methods of funding graduate education, including aligning with companies who offer financial assistance for graduate school or the repayment of a loan through service.

For the programs that are deemed to have both low numbers of URMs and little to no support for their students, an individualized diversity plan can be implemented through multiple types of analysis. Whatever type of analysis is chosen, facilitating faculty and staff dialogue in the examination of what they can do to improve their program in the overlapping realms of student support and access can be contentious. In an effort to maintain collegiality, I recommend that an external person serve in the capacity of the facilitator. If indeed the program/department can come to consensus on how to handle such a complex problem, perhaps the solutions and pragmatic action that help them get to the solution will then have stakeholder buy-in.

In an effort to establish a foundation for change, the programs and departments that are invested in making change (and those professionals working with them) will have to be systematic and systemic in their approach. A consideration of the faculty and staff who can contribute to the goal of inclusivity, along with the rules (institutional policies), responsibilities (position descriptions), and programmatic goals will help direct what can (and perhaps cannot) be accomplished (Bolman \& Deal, 2017). (See Table 5.)

Table 5. Emphasis on Financial Support for Programs with a Low Level of Diversity and a Low Level of Funding

\begin{tabular}{|c|c|}
\hline $\begin{array}{l}\text { Emphasis: Financial } \\
\text { Support }\end{array}$ & Diversity Low \\
\hline Funding Low & $\begin{aligned} \text { Programs D, H } \\
\text { - IDP (Individualized Diversity Plan) } \\
\circ \text { Political Framework } \\
\circ \text { Human Resources Framework } \\
\circ \text { Structural Framework } \\
\circ \text { Symbolic Framework }\end{aligned}$ \\
\hline
\end{tabular}

\section{Contribution to Practice}

Using this model, graduate programs are able to meet their nuanced needs by defining diversity for themselves in a way that is appropriate to their academic field. As described earlier, for instance, Asian Americans are not considered underrepresented in STEM; however, they might be considered underrepresented in other fields like education 
or the humanities at different geographic locations. Therefore, institutions need to compare diverse representation with peer programs at other institutions as opposed to only comparing them with those on their own campuses. The precision in awarding diversity funding model offered here provides administrators a pragmatic way to award diversity funding as shown in the completed rubric. (See Table 6.)

Table 6. Completed Four-Framed Rubric for Graduate Schools

\begin{tabular}{|c|c|c|}
\hline & Diversity High & Diversity Low \\
\hline Funding High & $\begin{array}{l}\text { Goal: Promote Success } \\
\text { - } \quad \text { Nominate for } \\
\text { Diversity and Equity } \\
\text { Awards. } \\
\text { - Support in Program } \\
\text { self-studies. } \\
\text { - Recognized as the } \\
\text { exemplar }\end{array}$ & $\begin{array}{l}\text { Goal: Develop Recruitment } \\
\text { Strategies } \\
\text { - GRE Search Service } \\
\text { - National Name Exchange } \\
\text { - McNair Directory } \\
\text { - California Forum for } \\
\text { Diversity } \\
\text { - Development of culturally } \\
\text { attuned programming and } \\
\text { mentorship } \\
\text { - Campus Visits }\end{array}$ \\
\hline Funding Low & $\begin{array}{l}\text { Goal: Support in } \\
\text { gathering resources for } \\
\text { assistantships/ } \\
\text { fellowships } \\
\text { - Grant proposal } \\
\text { support } \\
\text { - Fellowship search } \\
\text { - Examine } \\
\text { opportunities for } \\
\text { tuition waivers }\end{array}$ & $\begin{array}{l}\text { Goal: Develop an } \\
\text { Individualized diversity plan) } \\
\text { - Political Framework } \\
\text { - Human Resources } \\
\text { Framework } \\
\text { - Structural Framework } \\
\text { - Symbolic Framework }\end{array}$ \\
\hline
\end{tabular}

If implemented consistently this model will limit internal tension by being transparent across graduate programs. Participating faculty members and administrators will be able to see what other programs are doing to successfully recruit, retain, and graduate underrepresented students. Such transparency serves to improve the working environment for all involved and provides structure for professional collegiality as it relates to diversity support. It minimizes an institution's legal liability that could result from the calculated and uncapricious awarding of financial resources by relying on a dependable mathematical (albeit simple) method in granting financial resources. Finally, by 
incentivizing full participation, graduate programs can offer support that shows a comprehension of the benefits of a diverse learning community and provide a means for the graduate school's administration to help fulfill Estrada et al.'s (2016) essential first recommendation for promoting change: to track and increase awareness of institutional progress toward diversifying STEM.

\section{Conclusion}

I advise those charged with diversity and inclusivity initiatives within graduate school contexts to implement the following:

- A systematic review of academic programs, particularly along the variables of representation of diversity, as defined by the programs themselves and the resources available to support diversity;

- A conscious effort to promote, provide advocacy for, and celebrate the programs that are excelling along these two variables by nominating them for institutional diversity awards;

- An assessment of the issues that are limiting access to graduate education for historically underrepresented students by academic program, in terms of recruitment and retention through graduation;

The awarding of available resources that are specific to academic program needs. If departments have high funding but low representation, this is a recruitment issue, in which case, recruitment would be the focus; if retention is the issue, there are cultural and financial factors that may need to be addressed for students to graduate. Finally, in the event that a program is really struggling in both recruitment and financial support, it will be important to gather faculty, staff, and administration and consider a four-framed approach for reimagining what their program could look like in terms of diversity and inclusivity. It is important for the stakeholders to articulate the reasons it is important for them as a unique program. It is advisable to deliberate on why they value diversity and what level of commitment they have, expressed in tangible terms. To this end, institutions and programs may want to consider the amount of federal financial aid brought in by low SES Students (often used as a proxy for underrepresented students), the alignment of diversity support with institutional mission, and finally the fact that participation in this model is in alignment with agencies whose mission includes the development of an inclusive pool of researchers, educators, and students (NSF, 2008). Furthermore, as Gurin, Nagda, and Lopez (2004) state:

The discrepancy that racial and ethnic diversity on college campuses offers students for personal development and preparation for citizenship in an increasingly multicultural society depends on actual experience that students have with diverse peers. Just as positive educational benefits of racial and ethnic desegregation depended on real integration of children from different backgrounds, higher education institutions have to make use of racial/ethnic diversity by creating 
educational programs that bring diverse students together in meaningful, civil discourse to learn from each other. (p. 32)

Considering the multiple benefits of diversity, whether it is for reasons related to social justice and community restitution, improving all students' ability to work in a $21^{\text {st }}$ century context, or the utility of using multiple perspectives to solve complex problems and issues, graduate schools are uniquely positioned to offer support. It may be as simple as aligning with the need to broaden participation; there are multiple reasons, however, that diversity and inclusivity are essential parts of higher education. As the nation moves to a more diverse society, it will be important for programs and departments who employ research faculty and serve students from communities underrepresented in graduate education to be intentional in recruitment, retention, and graduation of these URM students in a fiscally responsible and calculated way.

\section{Notes}

1. This social construction of race is problematic in that different subgroups of these delineations, including Pacific Islanders and Southeast Asians, are underserved.

2. CGS is the only national organization in the United States that is dedicated solely to the advancement of graduate education and research. (About CGS, n.d.)

\section{References}

About CGS. (n.d.). Retrieved from http://cgsnet.org/about-cgs

Allen-Ramdial, S. A. A., \& Campbell, A. G. (2014). Reimagining the pipeline: Advancing STEM diversity, persistence, and success. BioScience, 64(7), 612-618.

Augoustinos, M., Tuffin, K., \& Every, D. (2005). New racism, meritocracy and individualism: Constraining affirmative action in education. Discourse \& Society, 16(3), 315-340.

Bolman, L. G., \& Deal, T. E. (2017). Reframing organizations: Artistry, choice, and leadership. Hoboken, NJ: Jossey-Bass.

Briggs, C. (2017). The policy of STEM diversity: Diversifying STEM programs in higher education. Journal of STEM Education, 17(4), 5-7.

Chu, C. H. (2016). When Proportionality Equals Diversity: Asian Americans and Affirmative Action. Asian American Law Journal, 23, 99.

Diversity and Inclusion. (n.d.). Retrieved from https://cgsnet.org/diversity-and-inclusion

Duranczyk, I. M., Franko, J., Osifuye, S., Barton, A., \& Higbee, J. L. (2015). Creating a model for graduate student inclusion and success. Contemporary Issues in Education Research, 8(3), 147-158.

Estrada, M., Burnett, M., Campbell, A. G., Campbell, P. B., Denetclaw, W. F., Gutiérrez, C. G., ... \& Okpodu, C. M. (2016). Improving underrepresented minority student persistence in STEM. CBE-Life Sciences Education, 15(3), [es5]. https://doi.org/10.1187/cbe.16-01-0038 
Garces, L. M. (2012). Racial diversity, legitimacy, and the citizenry: The impact of affirmative action bans on graduate school enrollment. The Review of Higher Education, 36(1), 93-132.

Goldstein Hode, M., \& Meisenbach, R. J. (2017). Reproducing whiteness through diversity: A critical discourse analysis of the pro-affirmative action amicus briefs in the Fisher case. Journal of Diversity in Higher Education, 10(2), 162-180. http://dx.doi.org/10.1037/dhe0000014

Gurin, P., Dey, E. L., Hurtado, S., \& Gurin, G. (2002). Diversity and higher education: Theory and impact on educational outcomes. Harvard Educational Review, 72(3), 330-367.

Gurin, P., Nagda, B. R. A., \& Lopez, G. E. (2004). The benefits of diversity in education for democratic citizenship. Journal of Social Issues, 60(1), 17-34.

Inclusiveness. (n.d.). Retrieved from http://cgsnet.org/inclusiveness

Inouye, K. (2016). Asian Americans: Identity and the stance on affirmative action. Asian American Law Journal, 23(6), 145-167. doi:https://doi.org/10.15779/Z38HZ84

Jones, M., Yonezawa, S., Mehan, H., \& Ballesteros, E. (2002). Shaping pathways to higher education. Educational Researcher, 31(2), 3-11

Luther, F. D., Seeberger, D. M., Phelan, S., \& Simpson, S. (2011). Diversity awards: Incentives for enhancing campus climate at the postsecondary level. Delta Kappa Gamma Bulletin, 77(4), 15-20.

Milem, J. F. (2003). The educational benefits of diversity: Evidence from multiple sectors. In M. Chang, D. Witt, J. Jones, \& K. Hakuta (Eds.), Compelling interest: Examining the evidence on racial dynamics in higher education (pp.126-169). Palo Alto, CA: Stanford University Press.

Milem, J. F., Clayton-Pedersen, A. R., Hurtado, S., \& Allen, W. R. (1998). Enhancing campus climates for racial/ethnic diversity: Educational policy and practice. The Review of Higher Education, 21(3), 279-302.

NCES. (n.d.). Digest of Education Statistics, 2012. Retrieved from https://nces.ed.gov/programs/digest/d12/tables/dt12_336.asp

NCES. (n.d.). Number of doctoral degrees earned in the United States by ethnicity in 2015/16. Retrieved from https://www.statista.com/statistics/185310/number-ofdoctoral-degrees-by-ethnicity/

NSF. (2008). Broadening participation at the National Science Foundation. Retrieved from

https://www.nsf.gov/od/broadeningparticipation/nsf_frameworkforaction_0808.pdf

Park, J. J., \& Liu, A. (2014). Interest convergence or divergence? A critical race analysis of Asian Americans, meritocracy, and critical mass in the affirmative action debate. The Journal of Higher Education, 85(1), 36-64.

Pascarella, E. T., \& Terenzini, P. T. (2005). How College Affects Students: A Third Decade of Research. Volume 2. Indianapolis, IN: Jossey-Bass, An Imprint of Wiley. 
U.S. Student Loan Debt Statistics for 2017. (2017, September 13). Retrieved from https://studentloanhero.com/student-loan-debt-statistics/

Villalpando, O. (2003). Self-segregation or self-preservation? A critical race theory and Latina/o critical theory analysis of a study of Chicana/o college students. Qualitative Studies in Education, 16(5), 619-646.

Whittaker, J. A., \& Montgomery, B. L. (2014). Cultivating institutional transformation and sustainable STEM diversity in higher education through integrative faculty development. Innovative Higher Education, 39(4), 263-275.

Yosso, T. J., Parker, L., Solorzano, D. G., \& Lynn, M. (2004). Chapter 1: From Jim Crow to affirmative action and back again: A critical race discussion of racialized rationales and access to higher education. Review of Research in Education, 28(1), 1-25.

\section{Author Contact}

Sweeney Windchief: sweeney.windchief@montana.edu

Adult \& Higher Education - 139 Reid Hall, Montana State University, Bozeman, Montana 59718, U. S. A. 